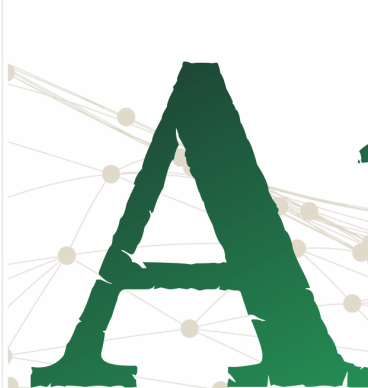

ISSN n² 2526-8031

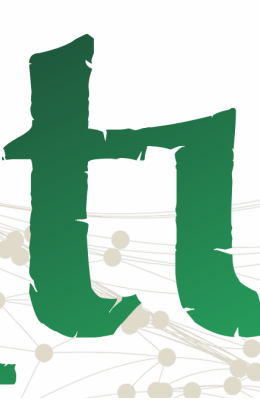

tur

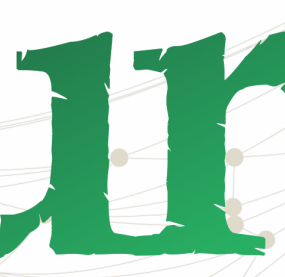

Revista

Pan-Amazônica

de Comunicação

Vol. 3, n. 3, Setembro-Dezembro. 2019

\title{
A INTENCIONALIDADE NAS NOTÍCIAS FALSAS: A NOTA DE REPÚDIO COMO ESTRATÉGIA DE DEFESA DO JORNALISMO NA ERA DAS FAKES NEWS
}

Intentionality in fake news: the repudiation note as a defense strategy of contemporary journalism

Intencionalidad en noticias falsas: la nota de rechazo como estrategia de defensa del periodismo contemporáneo

\section{Maria Luciene Sampaio Barbosa'}

Vilso Junior Santi ${ }^{2}$

\section{RESUMO}

Este artigo discute através do estudo de caso, a utilização da Nota de Repúdio como estratégia do jornal online Roraima em Tempo na defesa e resgate da credibilidade das notícias produzidas e divulgadas pelo jornalismo digital na era das fakes news. Com a publicação da nota de repúdio, levantou-se a questão se as fakes news causam preocupação e abalam a credibilidade do jornalismo online. Analisar esse mecanismo de defesa e repúdio utilizado pelo jornal abre a discussão sobre a intencionalidade das notícias falsas disseminadas na web. Essa análise foi feita tomando por aporte teórico o pensamento de Norbert Elias e John L. Scotson (2000) que tratam sobre relações de poder e Pierry Lévy $(2003 ; 2007)$ que aponta para as mudanças na forma de se comunicar e nas relações ocasionadas pelo ciberespaço. A nota de repúdio no jornal Roraima em Tempo

\footnotetext{
1 Mestranda do Programa de Pós-Graduação em Comunicação da Universidade Federal de Roraima (PPGCOM - UFRR). Especialista em Jornalismo Digital e jornalista em Roraima. E-mail: luciene7sampaio@gmail.com

${ }^{2}$ Professor-Doutor, Pesquisador no Programa de Pós-Graduação em Comunicação da Universidade Federal de Roraima (PPGCOM - UFRR). E-mail: vjrsanti@gmail.com.
} 


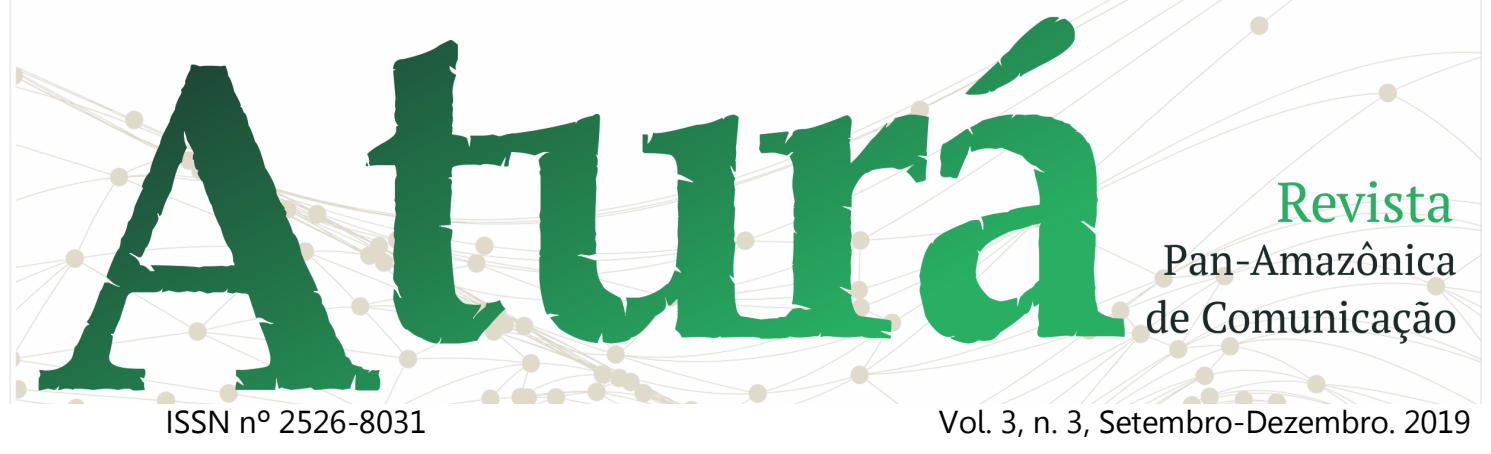

abriu espaço para uma discussão latente sobre a proliferação das notícias falsas, obrigando o veículo de comunicação a utilizar estratégias de defesa para reafirmar que o conteúdo por ele veiculado é verdadeiro e merece credibilidade.

PALAVRAS-CHAVE: Intencionalidade nas notícias; Notícias falsas; Nota de repúdio.

\begin{abstract}
This article discusses through the case study the use of the Note of Repudiation as a strategy of the online newspaper Roraima em Tempo in defending and restoring the credibility of the news produced and disseminated by digital journalism in the era of fakes news. With the release of the repudiation note, the question arose as to whether fakes news causes concern and undermines the credibility of online journalism. Analyzing this defense and repudiation mechanism used by the newspaper opens the discussion about the intentionality of fake news disseminated on the web. This analysis was made taking as theoretical basis the thought of Norbert Elias and John L. Scotson (2000) that deal with power relations and Pierry Lévy (2003; 2007) that points to the changes in the way of communicating and the relations caused by the cyberspace. The note of repudiation in the newspaper Roraima em Tempo made room for a latent discussion about the proliferation of fake news, forcing the media to use defense strategies to reaffirm that the content it conveys is true and deserves credibility.
\end{abstract}

KEYWORDS: Intentionality in the news; Fake news; Note of repudiation.

\title{
RESUMEN
}

Este artículo discute a través del estudio de caso el uso de la Nota de Repudio como una estrategia del periódico en línea Roraima em Tempo para defender y restaurar la credibilidad de las noticias producidas y difundidas por el periodismo digital en la era de las noticias falsas. Con el lanzamiento de la nota de repudio, surgió la pregunta de si las noticias falsas causan preocupación y socavan la credibilidad del periodismo en línea. El análisis de este mecanismo de defensa y repudio utilizado por el periódico abre la discusión sobre la intencionalidad de las noticias falsas difundidas en la web. Este análisis 


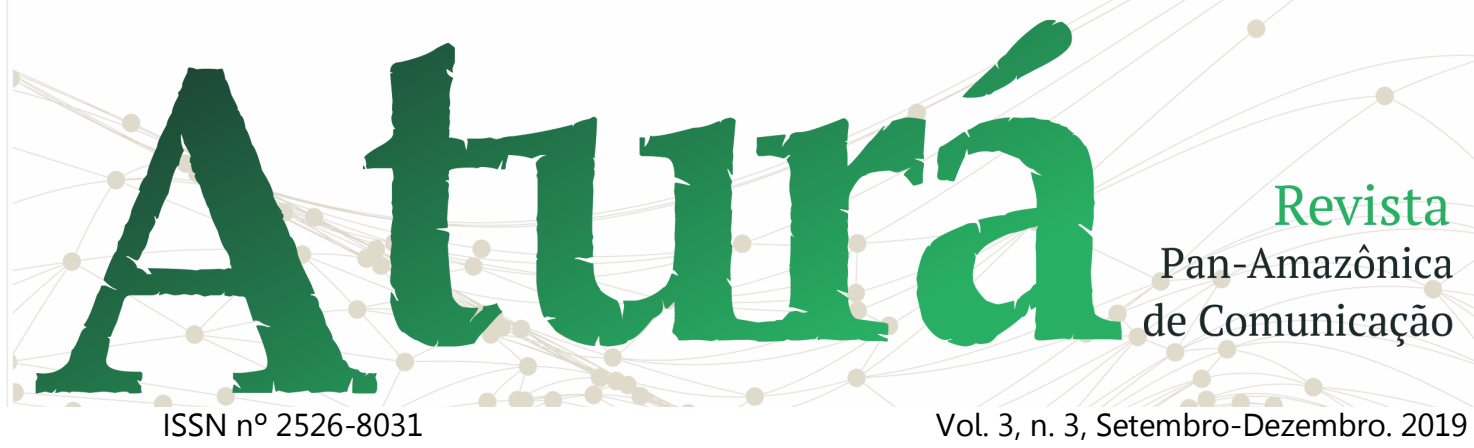

se realizó tomando como base teórica el pensamiento de Norbert Elias y John L. Scotson (2000) que se ocupan de las relaciones de poder y Pierry Lévy $(2003 ; 2007)$ que señala los cambios en la forma de comunicarse y las relaciones causadas por el ciberespacio La nota de repudio en el periódico Roraima em Tempo dejó espacio para una discusión latente sobre la proliferación de noticias falsas, obligando a los medios a usar estrategias de defensa para reafirmar que el contenido que transmite es verdadero y merece credibilidad.

PALABRAS CLAVE: Intencionalidad en las noticias; Noticias falsas; Nota de repudio.

Recebido em: 22.06.2019. Aceito em: 09.08.2019. Publicado em: 01.09.2019. 


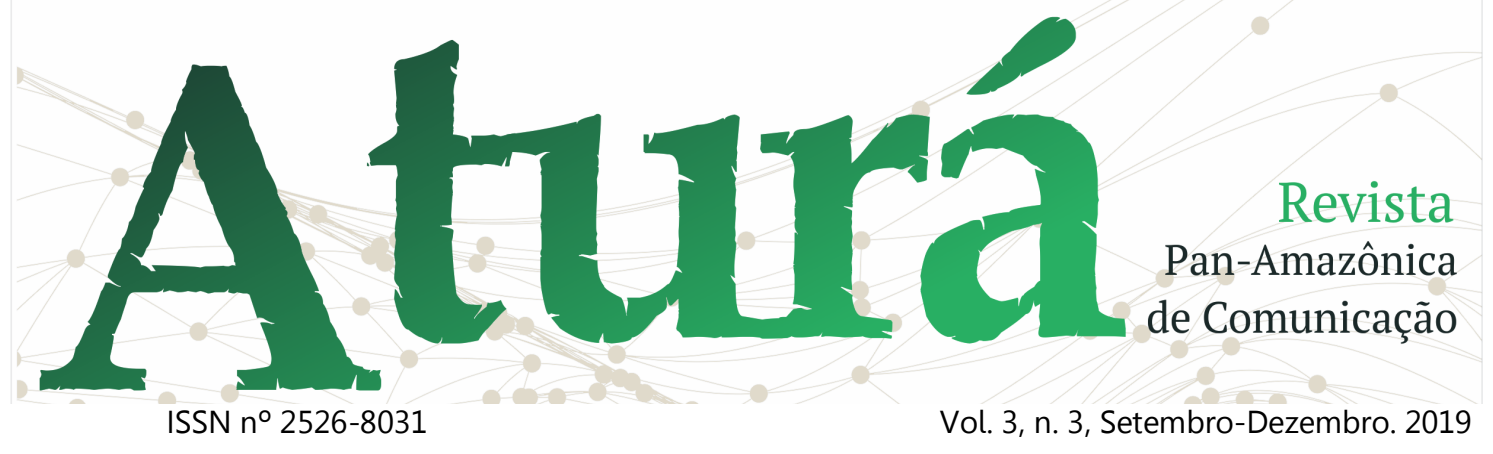

\section{Introdução}

Ao ser alvo da atuação da fake news, a reportagem do jornal online Roraima em Tempo, abordava assunto político local, com o título: "Mais de 60 testemunhas serão ouvidas nos processos que investigam Denarium por supostos crimes" ${ }^{\prime 3}$, ao ser manipulada a informação ganhou nova narrativa de ataque à administração estadual envolvendo uma deputada federal do PSDB de Roraima.

Para combater a disseminação da informação falsa, o jornal online, lançou na sua plataforma e no WhatsApp uma nota oficial condenando a ação da fake news em deturpar as informações contidas na reportagem.

No Brasil todas as esferas de representação de poder como o Executivo, Legislativo e Judiciário foram alvos de informações falsas ou incorretas. No mês de junho de 2019, o Supremo Tribunal Federal (STF) lançou o "Painel Multissetorial de Checagem de Informações e Combate a Fake News" ${ }^{4}$. 0 painel reuniu representantes da imprensa,

\footnotetext{
${ }^{3}$ Disponível em :

<https://roraimaemtempo.com/noticiaslocais/mais-de-60-testemunhas-serao-ouvidasnos-processos-que-investigam-denarium-porsupostos-crimes,295738.jhtml> .Acesso em 27 de mai. de 2019

${ }^{4}$ Disponível em

<https://g1.globo.com/politica/noticia/2019/06/1 1/stf-lanca-painel-de-combate-a-informacoesfalsas.ghtml >. Acesso em: 13 de jun. 2019
}

associações de juízes e tribunais superiores para combater as informações falsas que circulam na internet e redes sociais.

Diversos jornais e agencias se uniram para fazer checagem das notícias e combater as fakes news. Foram criados sites e projetos para investigar e apurar as informações que circulam no ambiente virtual são verdadeiras.

No entanto, quando se recebe uma informação, poucos usuários recorrem a verificação. De acordo com pesquisa realizada em outubro de 2018 pelo instituto Ipsos $^{5}$ em 27 países, revela que $62 \%$ dos brasileiros acreditavam em uma notícia, que na verdade era boato. Depois do Brasil vem Arábia Saudita e Coreia do Sul com 58\% de aceitações de notícias falsas.

Na área da política a disseminação e o compartilhamento de boatos se tornam latentes. Nas eleições de 2018, o Tribunal Superior Eleitoral firmou acordo com representantes de dez partidos para evitar a proliferação de notícias falsas durante a campanha eleitoral. Acordo que não surtiu efeito nenhum.

A fake news surge como manipulação para fomentar o debate político nas redes sociais. Segundo Träsel

\footnotetext{
${ }^{5}$ Disponível em:<https://www.valor.com.br/brasil/5911993/bra sileiro-e-o-povo-que-mais-acredita-em-boatosaponta-pesquisa >. Acesso em: 13 de jun. 2019
} 


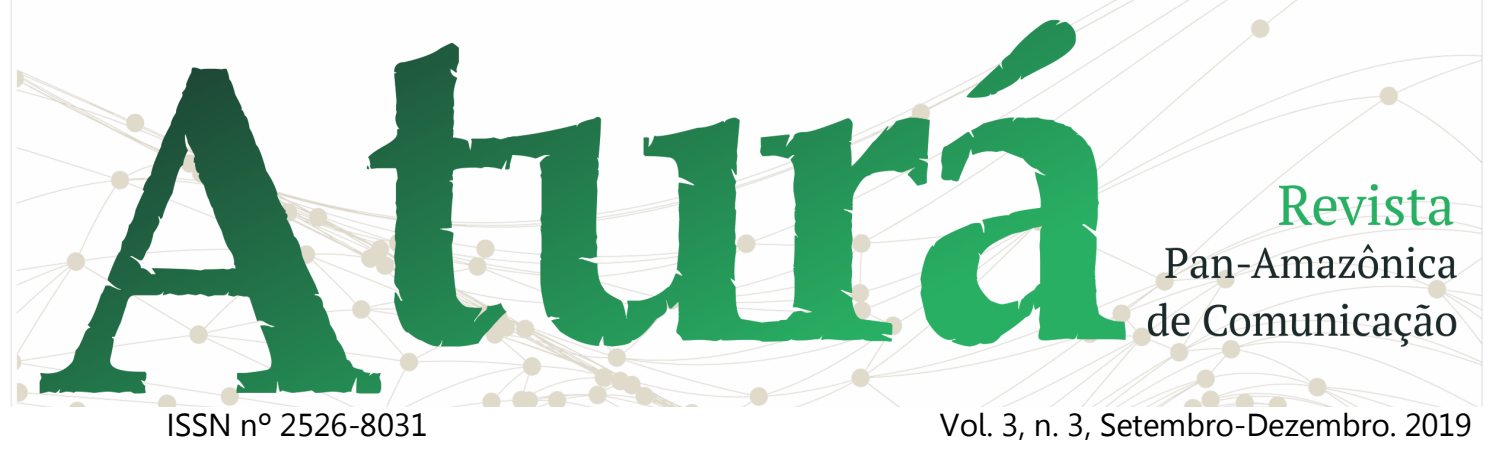

(2018), a disseminação de notícias falsas ganhou o nome de fake news, em outubro de 2014, quando o jornalista Craig Silverman, se deparou com a informação que uma cidade do Texas estaria de quarentena depois de uma família contrair ebola. Passados, dois anos, na eleição para presidente dos Estados Unidos esse termo retornou, mas desta vez para classificar qualquer informação verdadeira ou falsa sobre os adversários políticos do candidato Donald Trump.

No entanto, a veiculação da desinformação na esfera política prevalece também fora do período eleitoral. A fake news é utilizada como instrumento político e de poder para disseminar uma ideologia, favorecer ou denegrir a imagem de algum político ou agente público.

\section{Jornalismo em ambiente digital}

As mudanças movem as pessoas. Segundo Lévy e Lemos (2010), ao longo dos séculos, o homem utilizou vários artefatos para melhorar sua comunicação. Usou as imagens, a escrita, o alfabeto, a imprensa e hoje o ciberespaço. $O$ conceito foi difundido por Pierre Lévy (2007, p.18), como "nuevo espacio de comunicación, de sociabilidad, de organización y de transacción, pero también nuevo mercado de la información y del conocimiento".
Neste cenário, as transformações tecnológicas acarretam consequências no processo de informação. O canal da comunicação para levar uma mensagem não se utiliza mais tubos da velha TV ou nas ondas sonoras do rádio, como por exemplo, o conteúdo se encontra nas nuvens, no ciberespaço.

En la actualidad, es mucho más obvio que las nuevas modalidades de la cultura digital derivan de processos de transformación revolucionarios que se han desencnadeado a partir del desarrollo de las nuevas TIC digitales $y$ es históricamente previsible que conduzcan a trasnformaciones y consecuencias de tanto o mayor alcance y trascendencia que la revolución cultural operada por la escritura. (MEDINA, 2007, p. 09).

Com a evolução da internet, os jornais tradicionais migraram para a plataforma on line. Em 1995, o Jornal do Brasil foi o primeiro veículo do país a oferecer conteúdo em formato digital. "A iniciativa foi seguida por diversos outros que, atentando-se para a nova tendência, começaram a considerar a convergência como mecanismo de publicação de conteúdo" (SPANNENBERG, BARROS e BELAFONTE, 2016, p. 230).

$\mathrm{O}$ texto continua sendo à base da notícia no jornalismo online, com novas ferramentas para melhor compreensão do leitor. O conteúdo textual contribui para conversação do leitor com a informação. A sequência como se apresenta o texto 


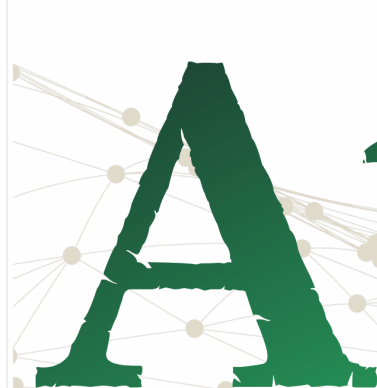

ISSN n $2526-8031$
Revista

Pan-Amazônica

de Comunicação

Vol. 3, n. 3, Setembro-Dezembro. 2019

não perdeu a essência das técnicas do jornalismo, apresentadas na pirâmide invertida com as perguntas básicas (Quem? Onde? O que? Quando? Como e Porquê). Segundo Canavilhas (2006, p. $02)$, "as notícias passam a ser produzidas com recurso a uma linguagem constituída por palavras, sons, vídeos, infografias e hiperligações, tudo combinado para que o utilizador possa escolher o seu próprio percurso de leitura".

Para o leitor escolher o ritmo de leitura, o conteúdo textual é produzido por uma sequência de blocos. Canavilhas (2014, p. 06) explica que o leitor tem a liberdade de escolher o Como e o Porquê do fato; "o texto transforma-se numa tessitura informativa formada por um conjunto de blocos informativos ligados através de hiperligações (links), ou seja, num hipertexto". O hipertexto possui diversas ferramentas que permitem maior análise da leitura.

A interatividade ganhou espaço na plataforma do jornalismo digital. Abriu-se a oportunidade para as pessoas comentar, criticar um conteúdo, sugerir reportagens enviando mensagens ou conteúdos para as redações. Rosto (2014) destaca que existem dois tipos de interatividade; uma seletiva centrada no receptor e outra denominada comunicativa o "utilizador" é um produtor de conteúdo.

[...] a interatividade é um conceito ponte entre o meio e os leitores/utilizadores, porque permite abordar esse espaço de relação entre ambas as partes e analisar as diferentes instâncias de seleção, intervenção e participação nos conteúdos do meio. Insere-se nessas zonas de contacto entre jornalistas e leitores, que as tecnologias têm alargado e simplificado (ROSTO, 2014, p. 53).

Outra característica marcante do jornalismo online é a instantaneidade das informações que são divulgadas na web. A rapidez em divulgar a notícia acirra a concorrência entre os sites de notícias. O "tempo real", ganhou espaço para a informação em primeira mão. Com advento da web 2.0 as pessoas passaram a produzir conteúdos que são postados nas redes sociais ou enviados para os sites de notícias.

A participação do público está sendo fundamental na instantaneidade em informar. "Esta é uma qualidade que se faz sentir em todas as notícias, em que os usuários podem agora ultrapassar o jornalista e a estória, chegar à testemunha, à cena; ao que está ocorrendo no momento" (BRADSHAW, 2014, p. 111).

O jornalismo no ambiente virtual adquiriu essas particularidades na publicação da notícia. Com o avanço da tecnologia esse modelo continua a ser formatado porque a tecnologia continua em pleno desenvolvimento. O jornalista tem um grande desafio pela frente em se conectar a cada dia com os usuários e 


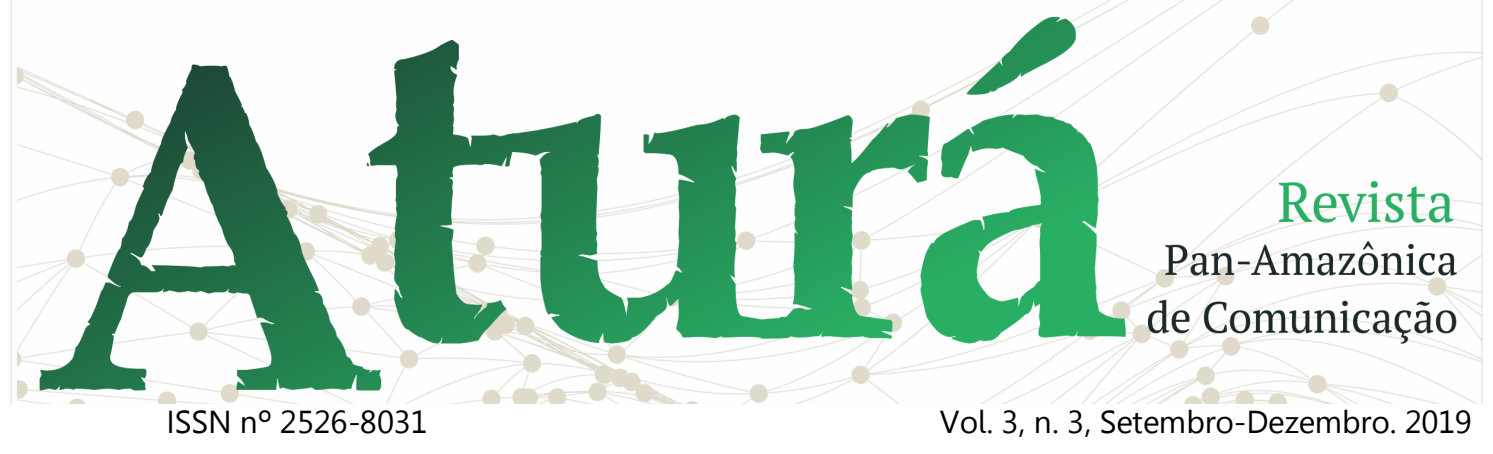

transformar conteúdo em informação segura e confiável.

\section{Fakes news e fofocas como traços da relação de poder}

A disseminação das fakes news tem colocado em dúvida a veracidade das notícias que circulam no ciberespaço. Com o advento da internet 2.0, o processo de compartilhamento ficou mais fácil e os usuários têm a liberdade em produzir conteúdos e publicar nas plataformas on line.

Segundo Levy (2003, p. 28) essa interação das pessoas e o intercâmbio de informações proporcionam a criação da inteligência coletiva, "[...] uma inteligência distribuída por toda parte, incessantemente valorizada, coordenada em tempo real, que resulta em uma mobilização efetiva das competências".

Na possibilidade de a produção de conteúdo ser feita por qualquer usuário da Web há alguns desafios. Sabe-se que, com a postagem de apenas um vídeo ou foto sem atenção às regras jornalísticas, porém com forte apelo emocional, tornase possível a formação de certa audiência digital, a qual realiza diversos comentários sobre o assunto. Não sendo raro que 0 assunto ultrapasse a esfera digital e torne-se assunto nas ruas.

Essa mudança no modo de compartilhar informações nas redes sociais tem ocasionado em alguns casos

Não interessa se as informações são verdadeiras ou plausíveis de verificabilidade uma vez que os indivíduos estão essencialmente interessados em corroborar certa visão do que mundo e em partilhar informações que vão ao encontro das suas próprias expectativas, estereótipos ou preconceitos (TREVIOT; BRIN e PRIOR, 2019, p. 03).

O usuário se depara com a superabundância de informações, fatos e opiniões. As escolhas passam a ser subjetivas e emocionais. Esse comportamento num mundo cheio de histórias e comentários com viés de manipulação política tornou-se latente para chamar de era da "pós-verdade".

Pós-verdade não é o mesmo que "mentiras" ou "informações falsas", mas a validação de determinada informação não pela objetividade dos fatos, mas pelo apelo às emoções e crenças pessoais, num cenário em que o poder da verdadeira interpretação estaria com a coletividade social (ESTEVÃO e FARIAS, 2008, p. 07).

As notícias circulam livremente pelas redes sociais. Nas eleições de 2018, - WhatsApp tornou-se a principal ferramenta para disseminação das fakes news. Uma pesquisa realizada pela Idea 


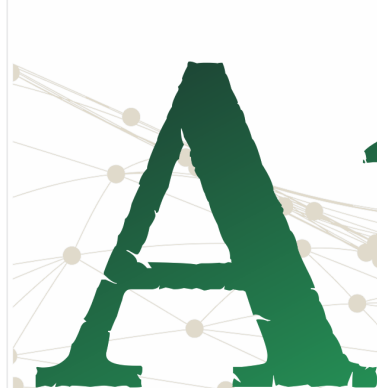

ISSN n $2526-8031$

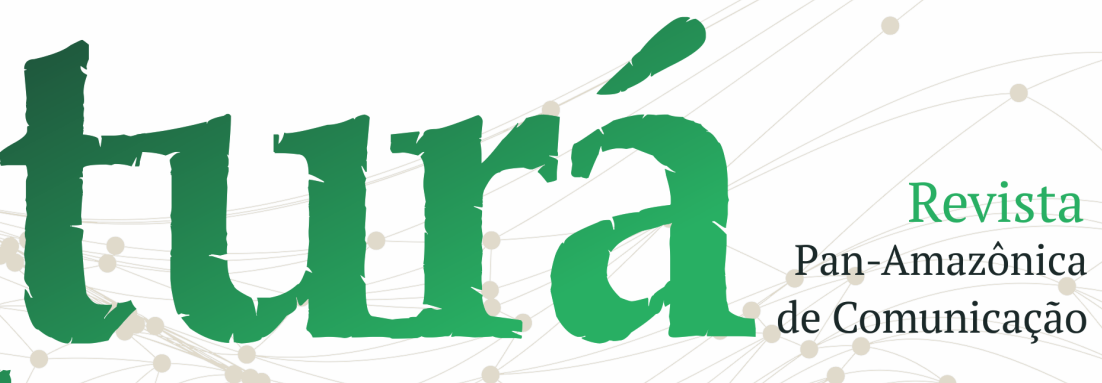

Vol. 3, n. 3, Setembro-Dezembro. 2019
Big Data ${ }^{6}$ divulgada no mês de junho de 2019, revela que cerca de dois terços dos brasileiros afirmaram terem recebido mensagens falsas pelo WhatsApp durante a campanha eleitoral.

A mesma pesquisa mostra que a internet via celular é a principal fonte de notícias para $32 \%$ das pessoas, perdendo apenas para a TV, com $36 \%$. O Rádio é a principal fonte de informação para $10 \%$ das pessoas, os jornais impressos, para $6 \%$.

O WhatsApp é um aplicativo que foi criado no ano de 2009. Em 2014 o Facebook comprou a empresa. O aplicativo é grátis e pode ser instalado em qualquer telefone móvel. Disponibiliza envio de mensagens, áudio, vídeo e chamadas. Segundo informações do próprio site do WhatsApp. Mais de 1 bilhão de pessoas, em mais de 180 países usam o aplicativo.

As notícias falsas produzidas e compartilhadas por perfis que possuem milhares de seguidores garantem poder, vantagem e promovem uma posição de superioridade sobre os usuários. Influenciando por meio de curtidas e compartilhamentos os demais seguidores. Muitas vezes, o conteúdo causa julgamento precipitado e provoca

\footnotetext{
${ }^{6}$ Disponível em:

$<$ https://amazonasatual.com.br/choveu-fakenews-no-whatsapp-de-brasileiros-na-eleicaorevela-pesquisa/>. Acesso em: 18 de jun. 2019
}

preconceito, violência verbal e discriminação.

A internet é o canal que prolifera as inverdades sobre os indivíduos ou grupos, dadas pela própria característica técnica em alcançar em velocidade milhões as pessoas. O criador da world wide web, engenheiro britânico Tim Berners-Lee, em entrevista publicada no dia 12 de março de 20197, ao falar sobre os 30 anos de criação da web, criticou o mau uso que as pessoas fazem da internet. Numa carta de proposta e compartilhada em vários sites do mundo, Berners-Lee, afirmou que a rede criou oportunidades para cometer vários golpes, crimes e espalhou ódio:

$E$ ao mesmo tempo em que a Web foi criando oportunidades, dando voz aos grupos marginalizados e facilitando nossas vidas diárias, também criando oportunidades para golpistas, dando vozes que se espalham e tornando mais fácil a perpetração de todos os tipos de crime (BERNERS- LEE, 2019, p. 01).

A maneira como a Web está sendo utilizada pelas fakes news para prática de crimes como calunia, injúria, difamação e um mecanismo para depreciar grupos numa constante luta de poder. Para Elias e Scotson (2000, p.13), as mensagens mentirosas, como as fofocas são consideradas um "instrumento poderoso"

\footnotetext{
${ }^{7}$ Disponível em :

$<$ https://webfoundation.org/2019/03/webbirthday-30/>. Acesso em 21/06/2019
} 


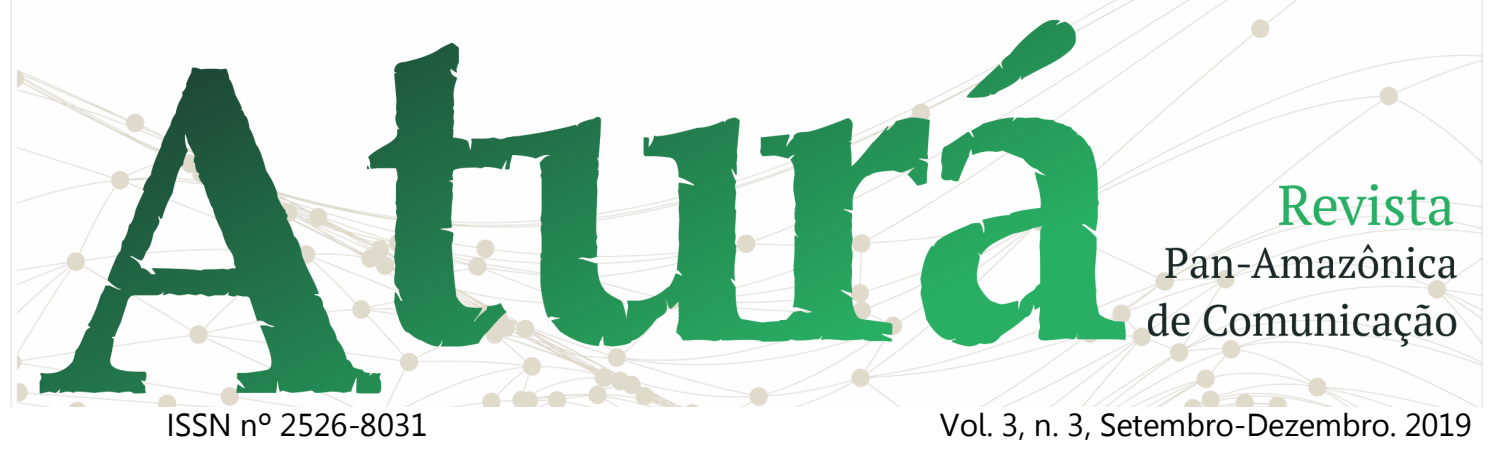

para fortalecer a presença de um grupo considerado economicamente e socialmente forte em detrimento aos grupos que não se encaixam com sua ideologia e comportamento.

As fofocas ou mexericos, como são classificados por Elias e Scotson (2000), moviam uma comunidade do interior da Inglaterra dividida em dois grupos: os Estabelecidos e Outsiders. A pesquisa foi realizada no fim da década de 1950 e no início dos anos 60. Os Estabelecidos formam uma classe de pessoa de boa moral, conduta e mantinham influência pela condição financeira, prestígio e poder. Os Outsiders formavam um grupo que não gozavam de uma boa moral que atendia os critérios de conduta determinados pelos Estabelecidos deveriam ser afastados do ciclo social.

Os moradores mais antigos (Estabelecidos) para continuar exercendo relação de poder e controle social diante das pessoas recém-chegadas (Outsiders), utilizavam as fofocas. Portanto, o fenômeno das fakes news não se apresenta como novidade na esfera social. A manipulação das informações é um traço das organizações humanas que existem há anos. Elias e Scotson (2000), descrevem dois tipos de fofocas para manter o poder de grupos dominantes. A fofoca depreciativa e a fofoca elogiosa.

A fofoca não é um "fenômeno independente", possui entrelaçamento envolvendo normas, crenças e relações comunitárias.

O uso comum nos inclina a tomar por "fofocas", em especial, as informações mais ou menos depreciativas sobre terceiros, transmitidas por duas ou mais pessoas umas às outras. Estruturalmente, porém, a fofoca depreciativa ।blame gossip é inseparável da elogiosa \pride gossip\ que costuma restringir-se ao próprio indivíduo ou aos grupos com que ele se identifica (ELIAS e SCOTSON 2000, p. 121).

Ao analisar o fluxo das fofocas na cidade do interior, o que mantinha os moradores unidos era um elemento de coesão. "A comunidade mais unida tinha canais mais adequados para a transmissão das notícias de interesse público e um número maior de interesses comuns" (ELIAS e SCOTSON 2002, p. 122).

Nas redes sociais, as mensagens deturpadas também unem um exercíto de internautas que compartilham, comentam ou curtem as mensagens para reiterar sua posição diante dos demais grupos espalhados na web.

$\mathrm{Na}$ mídia tradicional, a comunicação manipulada pelo capitalismo cria as condições para manter o poder e controle social. A massa sofre ação dos meios de comunicação e sendo estimuladas a se engajar por uma ideologia de dominação.

Todas as redes que interessam à comunicação de massa e a comunicação interpessoal, obedecendo a uma estrutura 


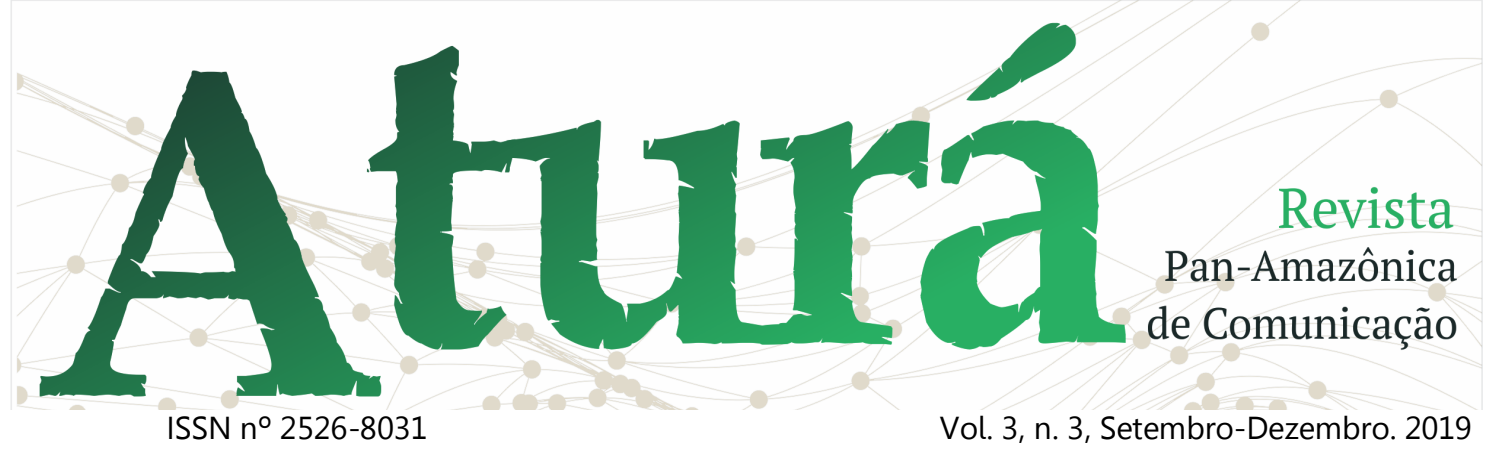

formal, são instrumentos de poder, estreitamente controlados na maioria dos casos, pois permitem encerrar uma população numa trama informacional que as super determina em relação às estratégias das organizações (RAFFESTIN, apud ZANETTI e REIS, 2017, p. 18).

O serviço em veicular notícia reafirma e fortalece a ideologia das classes hegemônicas. Segundo Maldonado (2016, p. 216), os meios de comunicação se transformaram no "príncipe eletrônico", "[...] para manter as estruturas anacrônicas e exercício político e de vida cultural".

Para Maldonado (2016, p. 213), o jornalismo oligárquico cria técnicas para manter-se no poder, como "enquadramento, agendamento, novos modos de montagem, estrutura sintética cartesiana do texto, modelos midiáticos mistos, recursos multimidiáticos e transmidiáticos".

A mudança da informação em notícia é considerada como um processo de etapas industrial. De acordo com Wolf (1994, p.161), é "constituída pelos estudos que analisam a lógica dos processos pelos quais a comunicação de massa é produzida e o tipo de organização do trabalho dentro da qual se efetua a "construção das mensagens". Portanto, para ser veiculada a notícia precisa passar por uma série de processo como seleção, apuração, produção e edição para chegar até as pessoas.
Neste cenário de manipulação, tendencioso e conflito sobre o verdadeiro papel da mídia tradicional, a desinformação gerada pelas fake news, configura um cenário de dúvidas sobre a notícia.

\section{Nota de Repúdio e o Jornal Roraima em Tempo}

O Jornal Roraima Em Tempo, surgiu no ano de 2016 com a versão impressa. O jornal era o único no Estado que mantinha circulação diária nos 15 municípios do estado de Roraima. A distribuição dos jornais era feita por meio de transporte alternativo que levava as tiragens para os respectivos municípios.

O Roraima Em Tempo enfrentou uma crise financeira passando a circular somente na capital Boa Vista.

Após as eleições de 2018 o jornal impresso sucumbiu e houve a migração para a versão on line. No dia 27 de março de 2019, o jornal digital, publicou em sua página uma nota de repúdio em fonte grande, além do padrão estabelecido para uma manchete de notícias para chamar a atenção do leitor.

Imagem 1: Nota de Repúdio 


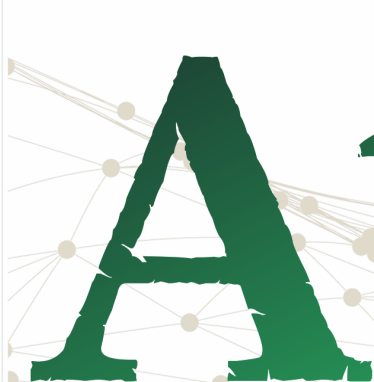

ISSN n² 2526-8031

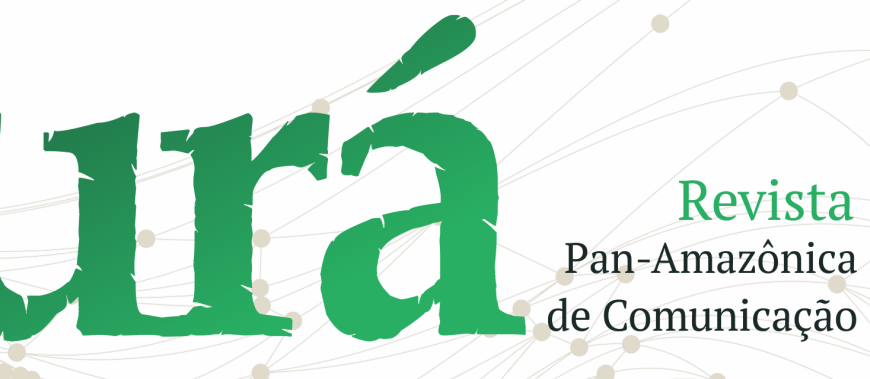

Vol. 3, n. 3, Setembro-Dezembro. 2019

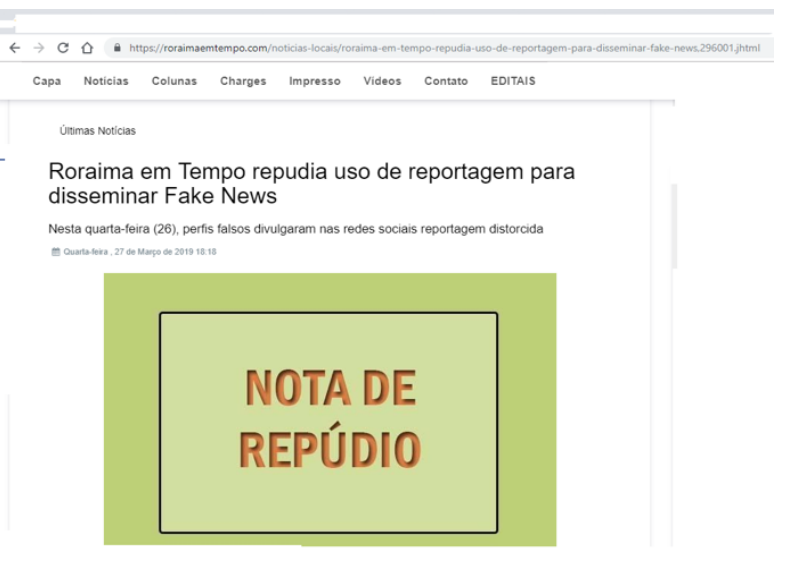

Fonte: encurtador.com.br/lyB58

O jornal online recorreu ao ato adotado pelas manifestações nas ruas. $O$ repúdio pode se configurar como vaia, apitaço, buzinaço e notas oficiais. São formas em demonstrar uma indignação por algum ato ou comentário. É uma estratégia de esclarecimento para resgatar a credibilidade e esclarecer fatos que foram distorcidos.

Com assinatura "Roraima em Tempo repudia o uso de reportagem para disseminar fake news", a nota foi utilizada para esclarecer que uma reportagem produzida pela equipe de jornalismo foi adulterada e disseminada pelos grupos WhatsApp. A nota assinada pela Redação esclareceu que o teor da reportagem não fazia oposição ao atual governo do estado de Roraima e nem havia citado o nome da Deputada Federal Shéridan de Oliveira (PSDB).

A reportagem publicada no dia 25 de março com o título "Mais de 60 testemunhas serão ouvidas nos processos que investigam Denarium por supostos crimes", assinada pelo jornalista Anderson Soares, abordava que a Justiça Eleitoral já havia determinado datas para ouvir as testemunhas de acusação e defesa envolvidas no processo que investiga suposta compra de votos durante a campanha eleitoral de 2018, do candidato ao governo do Estado, Antônio Denarium (PSL).

Denarium venceu o segundo turno das eleições ao cargo de governador. A reportagem informou que procurou $\mathrm{O}$ governo do Estado para ouvir todas as partes envolvidas. A Secretaria Estadual de Comunicação respondeu que o caso estaria sendo analisado pelo setor jurídico.

Nos grupos de WhatsApp a informação que circulou com o seguinte título "Denarium teme perder o cargo e começa o limpa no governo", no texto em forma de lead, estrutura jornalística para que o leitor tenha conhecimento inicial do que se trata a reportagem, apontava que o governador estava receoso em ser cassado e se esforçava para garantir o empenho de faturas para os empresários locais que haviam financiados a sua campanha eleitoral.

O texto fake incluiu o nome da Deputada Federal e presidente regional do PSDB, Shéridan Oliveira, cujo partido é o autor das denúncias contra Denarium. 


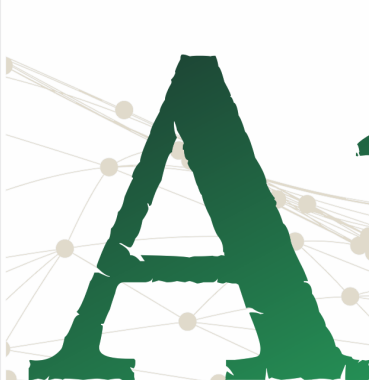

ISSN n²526-8031

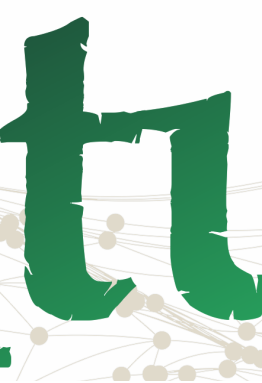

(t)

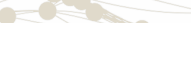

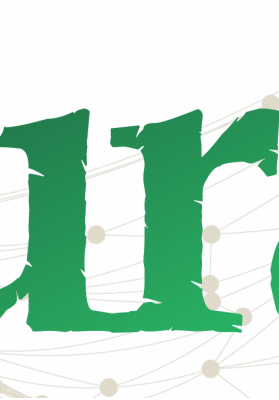

Vol. 3, n. 3, Setembro-Dezembro. 2019
As informações atribuíam à deputada uma negociação com o governador para retirar as denúncias e consequentemente conseguir recursos para financiamento da campanha eleitoral à prefeitura de Boa Vista.

O texto oferecia a opção para que - usuário acessasse o link real da reportagem do jornal on line. Induzindo as pessoas que ao lerem a narrativa com indicação de acesso ao link entenderem que a reportagem abordava que 0 governador estaria preocupado com a cassação e realizando ações duvidosas.

A notícia falsa foi disparada e compartilhada em vários grupos. A repercussão fez com que a Secretaria Estadual de Comunicação do Governo publicasse um material alertando que a notícia era falsa.

Imagem 2: Banner oficial Governo do Estado

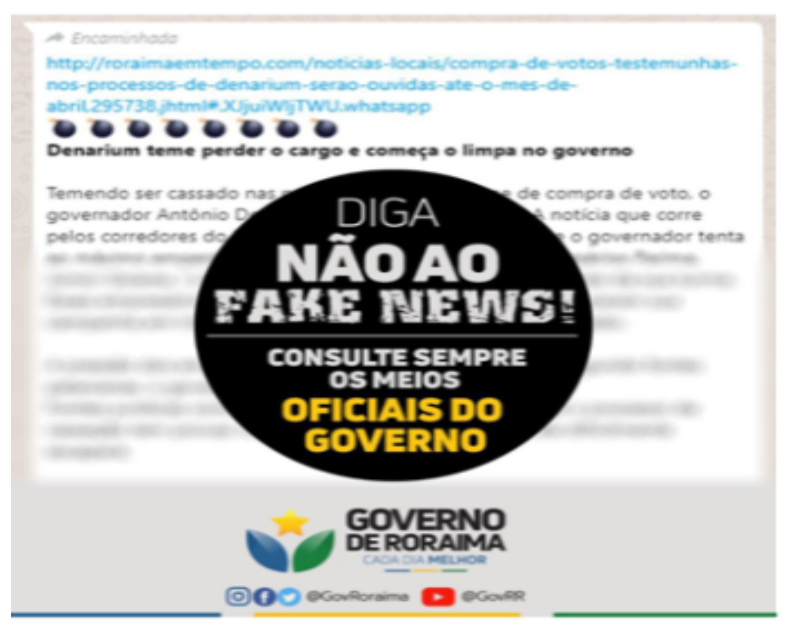

Fonte: whatshapp
As informações disseminadas pelas fake news possuíam coerência no texto e não apresentavam erros de grafia ou concordância. Apresentavam uma roupagem de notícia atendendo os critérios de noticiabilidade. Os autores dessas informações falsificadas trabalhavam com a intenção de persuadir, confundir, dividir a opinião das pessoas ou grupo político com intuito de causar insegurança jurídica e instabilidade na gestão governamental. A intencionalidade desse material revela uma guerra de poder para excluir determinado grupo que não se encaixa com as ideias e posições.

Posicionamento reconhecido pelo pesquisador Norbet Elias (2000) numa comunidade do interior de Inglaterra. Os moradores para manterem a hegemonia de poder utilizava a fofoca como traço para denigrir ou afastar os grupos sociais contrários as suas ideologias.

A propagação do texto falso atribuído a reportagem obrigou o jornal online a tomar algumas medidas para evitar maiores problemas. Além da publicação da nota de repúdio postada no site, o jornal teve que dissemina-la em vários grupos de WhatsApp para combater a informação errada e esclarecer o usuário.

A disseminação das notícias falsas viabilizadas pelas redes sociais aponta uma preocupação da mídia nesta era 


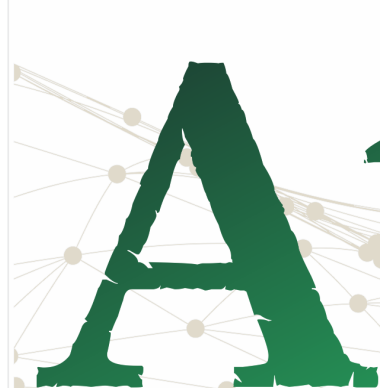

ISSN n $2526-8031$

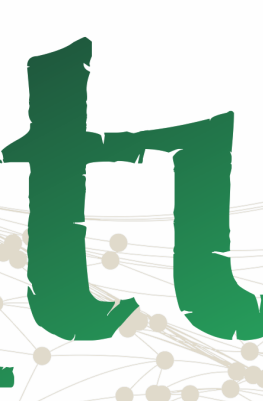

digital. Os meios de comunicação, que são capazes de denunciar irregularidades, fiscalizar a atuação do Legislativo, Executivo e Judiciário, elucidar casos, esclarecer dúvidas travam uma batalha árdua contra as fakes news.

É uma guerra de forças e relação de poder. É um mecanismo antigo usado para separar grupos e mover a opinião pública em favor ou desfavor de uma causa. O papel da imprensa negociável pela disputa acirrada da audiência e obtenção de lucros fizeram com que as atribuições dadas para os meios de comunicação em informar, retratar a veracidade e clareza dos fatos foi dando lugar ao espetáculo da notícia, iniciando um processo de desinformação.

A imprensa cerceada pela ideologia das oligarquias foi se tornando tendenciosa e falível em divulgar notícias de interesse social apegando-se aos assuntos que vendem mais rápido $\mathrm{e}$ tenham maior consumo entre os leitores e espectadores.

Com a disseminação das fakes news no ciberespaço os grandes veículos de comunicação se deparam com o desafio em combater as informações falsas e garantir o seu espaço como agente esclarecedor na sociedade. Neste momento de confronto entre as informações falsas, a imprensa utiliza estratégias de defesa para reafirmar que o conteúdo produzido, apurado, checado é verdadeiro, portanto, merece credibilidade.

A postura do jornal em publicar uma nota para repudiar a disseminação de notícias falsas é um alerta para o leitor. Para o jornal a postura adotada é uma forma de garantir audiência posicionando-se como veículo de comunicação que busca a verdade dos fatos. É autopromoção de uma imagem no mundo virtual buscando resgatar a credibilidade.

\section{Considerações finais}

Com base no estudo de caso da nota de repúdio publicada pelo Jornal online Roraima em Tempo, pode-se observar que a nota esclarece ao leitor que o conteúdo do jornal foi distorcido para prejudicar um grupo político, favorecer outro e influenciar a opinião da coletividade.

As relações sociais se caracterizam em suma pela forma das pessoas tentarem monopolizar o poder e depreciando uns aos outros que não apresentam interesse ou tragam algum incomodo pelo fato de não poder contribuir com seus ideais.

Essa guerra de tensão de caracteriza na política, área de maior repercussão das fakes news. Segundo Elias e Scotson (2000) a tensão entre poderes se dá entre partidos e governos. 


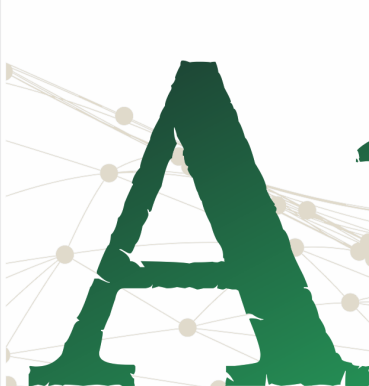

ISSN n²526-8031
Revista

Pan-Amazônica

de Comunicação

Vol. 3, n. 3, Setembro-Dezembro. 2019

No decorrer dessa relação, as pessoas acabam sendo Outsiders e Estabelecidos subordinados pelas regras, é um círculo de força estabelecendo uma relação diversificada onde o poder se concentra no saber.

Em ambos os sentidos, aqueles que monopolizam 0 acesso as informações e decisões asseguram para si mesmos certas fontes de superioridade em termos de poder e status. A destreza necessária para a aquisição de saber é uma dessas fontes (ELIAS e SCOTSON, 2000, p. 208).

Neste caso a informação se torna uma peça importante para monopolizar o poder de algum grupo. As fakes news alcançaram um potencial e provocam insegurança para os grupos de comunicação mediante a transmissão de notícias, mesmo sendo falsas, pois a maioria dos usuários não dispõe de tempo e nem possui hábito para averiguar a informação e fazer comparação entre uma e outra.

A imprensa busca mecanismos de defesa em resgate a credibilidade e combate as notícias falsas. É momento que precisa se reinventar para estar mais perto da sociedade e abandonar o jornalismo tendencioso com opiniões rechaçadas de partidarismo político.

Os jornais enfrentam um grande desafio em estar mais perto da sociedade e criar alternativas para entender o que as pessoas querem saber. Em alguns veículos de comunicação criaram a opção em trabalhar em parceria com as informações que circulam nas redes sociais. Abrindo espaço para ouvir mais o púbico e reduzindo a distância entre o usuário.

A mudança em fazer jornalismo provocada primeiramente pela web e consequentemente pelas fakes news, apresenta uma imprensa preocupada em resgatar a credibilidade pela veiculação da verdade. Lévy, (2018, p. 248) antevia os resultados favoráveis no ciberespaço no processo da transmissão das informações. "Novas formas de escrever, novas retóricas da interatividade são inventadas". Portanto, o futuro da web depende da responsabilidade que cada usuário em produzir informações.

Para o criador da internet, LeeBerneres, "se desistirmos de construir uma melhor web agora, então a web não terá falhado conosco. Nós teremos falhado na web" (2019, p.01). Não podemos, portanto, deixar o medo e a guerra de poder espalhar mentiras ou denegrir a imagem do outro. $O$ compromisso da imprensa pela verdade e credibilidade deve nortear os rumos para uma sociedade mais consciente e democrática. 


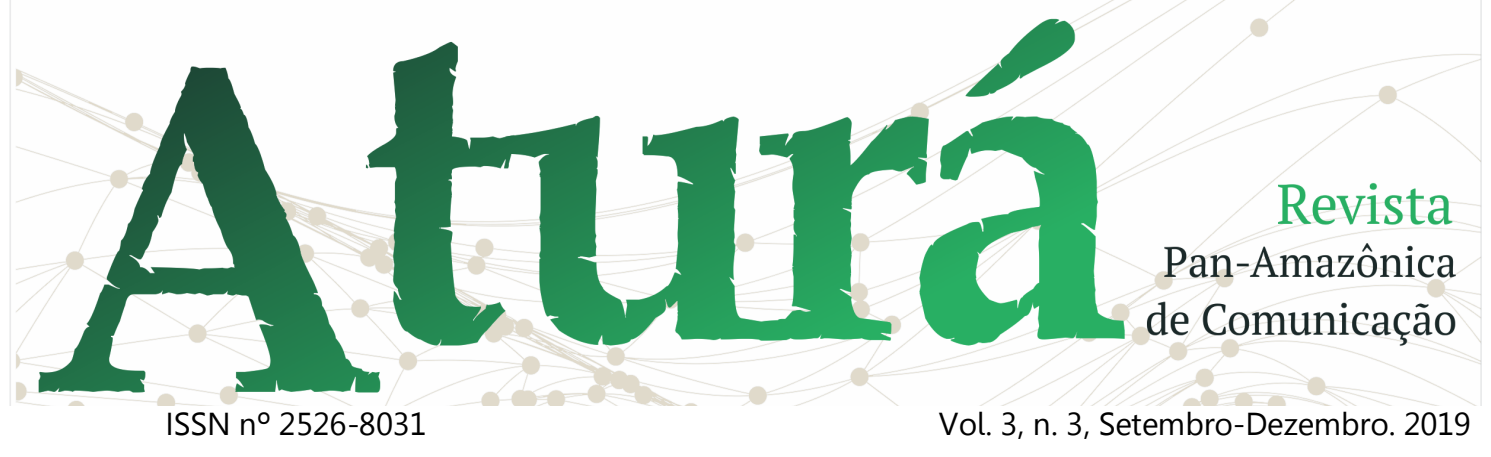

\section{Referências}

BASILE, Juliano. Brasileiro é o povo que mais acredita em boatos, diz pesquisa. Valor Econômico, São Paulo-SP, 08 de outubro de 2018. Política. Disponível em: <https://www.valor.com.br/brasil/591199 3/brasileiro-e-o-povo-que-mais-acreditaem-boatos-aponta-pesquisa >. Acesso em: 13 de jun. 2019

BERNERS-LEE, Tim. 30 anos depois, o que vem a seguir \#ForTheWeb? World Wide Web Foundation, Washigton- EUA. 12 de mar. de 2019. Disponível em :

$<$ https://webfoundation.org/2019/03/we b-birthday-30/>. Acesso em 21 de jun. 2019

BRADSHAW, Paul. Instantaneidade: Efeito da rede, jornalistas mobile, consumidores ligados e o impacto no consumo, produção e distribuição. In: CANAVILHAS, João Messias (Org). Webjornalismo: 7 características que marcam a diferença. Covilhã: Livros LabCom, 2014. p. 111-136.

BAPTAGLIN, L. A.; CHIERENTIN SANTI, V. J. As intervenções artísticas urbanas no circuito da arte em Roraima e o potencial comunicativo dos saberes artísticos amazônicos. Revista Observatório, v. 4, n. 4, p. 615-637, 29 jun. 2018.

CANAVILHAS, João Messias. Do jornalismo online ao webjornalismo: formação para a mudança. Revista
Comunicação e Sociedade. Universidade do Minho, n.10, 2006. Disponível em: $<$ revistacomsoc.pt/index.php/comsoc/arti cle/view/1159>. Acesso em: 15 de jun. 2019

DA REDAÇÃO: Um terço dos brasileiros checa veracidade de notícias. Veja On line, Brasília-DF, 14 de maio de 2018. Política. Disponível em: $<$ https://veja.abril.com.br/politica/umterco-dos-brasileiros-checa-veracidadede-noticias- aponta-pesquisa/>. Acesso em: 19 de jun. 2019.

DE ALMEIDA, T. A.; SANTI, V. J. Somos migrantes: o uso das redes sociais na produção midiática alternativa sobre a migração venezuelana em Roraima. Aturá - Revista Pan-Amazônica de Comunicação, v. 2, n. 1, p. 136-156, 2 jan. 2018.

D'AGOSTINO, Rosanne; OLIVEIRA, Mariana. STF lança painel de combate a informações falsas. G1, Brasília-DF, 11 de jun. de 2019. Política. Disponível em $<$ https://g1.globo.com/politica/noticia/20 19/06/11/stf-lanca-painel-de-combate-ainformacoes-falsas.ghtml $>$. Acesso em: 13 de jun. 2019

ELIAS, Norbert e SCOTSON, John. Os Estabelecidos e os Outsiderssociologia das relações de poder a partir de uma 


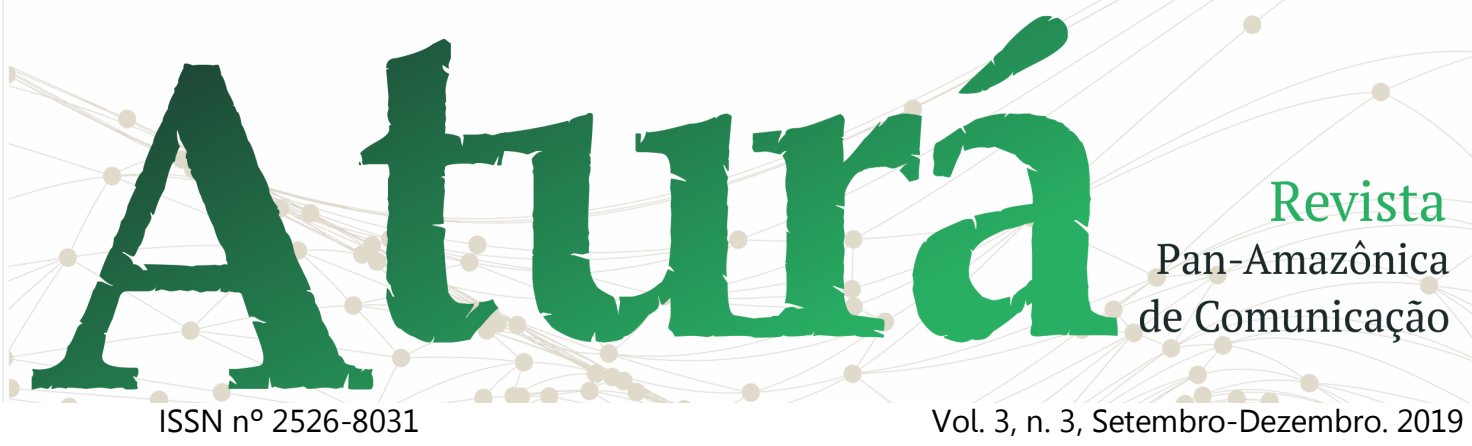

pequena comunidade. Rio de Janeiro. Ed. Jorge Zahar, 2000

ESTEVÃO, Flávia Gonçalves de Moura; FARIAS, Lídia. Conexão e "Pós-verdade": Propagabilidade da Desinformação?. Intercom - Sociedade Brasileira de Estudos Interdisciplinares da Comunicação $41^{\circ}$ Congresso Brasileiro de Ciências da Comunicação. Joinville, 02 de set. 2018. Disponível em: <http://portalintercom.org.br/anais/nacio nal2018/resumos/R13-2058-1.pdf>.

Acesso em: 19 jun. 2019.

FÉLIX, J. DE S.; SANTI, V. J. O uso da mídia televisiva por grupos e instituições religiosas no Brasil: uma análise da atuação da IURD na rede Record. Aturá Revista Pan-Amazônica de Comunicação, v. 2, n. 2, p. 245-260, 23 abr. 2018.

HOHLFELDT, Antônio. Martino, Luiz C. França, Vera Veiga. Teorias da Comunicação. Petrópolis, Rio de Janeiro. Ed. Vozes, 2001

LÉVY, Pierre. A inteligência coletiva: por uma antropologia do ciberespaço. 4. ed. São Paulo: Loyola, 2003.

LÉVY, Pierre. Cibercultura: la cultura em la sociedad digital. México: Anthoropos Editorial 2007.
MALDONADO, Alberto Efendy Gómez de La Torre. Transmetodologia em tempos de fascismo social, Revista Latinoamericana de Comunicación, n.133, $2016 . \quad$ Disponível em: <https://dialnet.unirioja.es/servlet/articul o?codigo $=5792173>$. Acesso em 15 de maio de 2019.

MEDINA, Manoel. Cibercultura: La cultura de la sociedade digital/ Pierre Lévy. México: Anthoropos Editorial, 2007.

MELLO, Patrícia. "Choveu" Fake News no WhatsApp de brasileiros na eleição, revela pesquisa. Atual Amazônia. ManausAM, 20 de maio de 2019. Política. Disponível em: $<$ https://amazonasatual.com.br/choveufake-news-no-whatsapp-de-brasileirosna-eleicao-revela-pesquisa/>. Acesso em: 18 de jun. 2019

ROSTO, Alejandro. Interatividade: definições, estudos e tendências. In: Canavilhas, João (org). Webjornalismo 7 característica que marcam a diferença. Covilhã. Editora: LivrosLab, 2014

SANTOS, L. C. C.; SANTI, V. J. Relações sincrônicas e diacrônicas na prática jornalística: do período industrial ao pósindustrial. Aturá - Revista Pan-Amazônica de Comunicação, v. 1, n. 3, p. 62-86, 10 dez. 2017. 


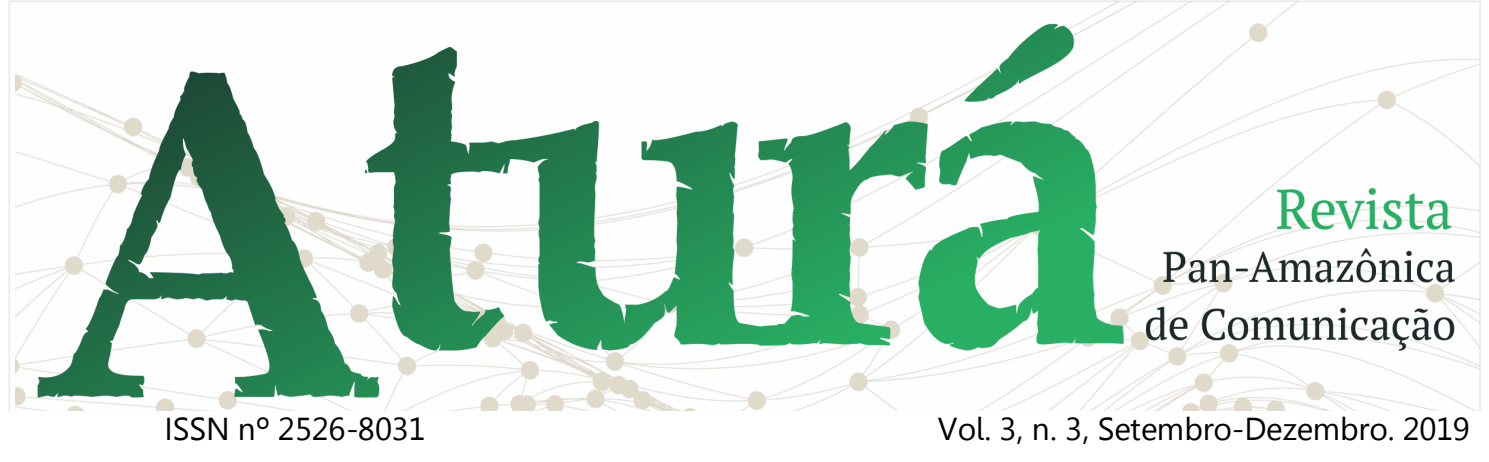

SANTI, V. J.; LUZ, W. O. DA. O uso das redes sociais pelo governo de Roraima como ferramenta na prática jornalística. Aturá - Revista PanAmazônica de Comunicação, v. 1, n. 2, p. 145-167, 30 ago. 2017.

SOARES, Anderson. Mais de 60 testemunhas serão ouvidas nos processos que investigam Denarium por supostos crimes. Roraima em Tempo, Boa Vista-RR, 25 de mar. de 2019. Notícias locais. Disponível em

$<$ https://roraimaemtempo.com/noticiaslocais/mais-de-60-testemunhas-seraoouvidas-nos-processos-que-investigamdenarium-por-supostosrimes,295738.jhtml> Acesso em 02 de mar. de 2019

SPANNENBERG, Ana Cristina Menegotto; BARROS, Cindhi Vieira Belafonte. Do impresso ao digital: a história do Jornal do Brasil. Revista Observatório. Vol. 2, Especial 1, maio. 2016. Disponível em : https://hal.archives-ouvertes.fr/hal01560361/document.> . Acesso em: 15 jun. 2019

SOBRE O WHATSAPP. WhatsApp. Disponivel em <https://www.whatsapp.com/about/?lang $=p t$ br $>$. Acesso em: 18 de jun. de 2019

THEVIOT, Anaïs; BRIN, Colette; PRIOR Hélder. Social Média, desinformação em jornalismo em Campanhas Eleitorais. Plataforma 9- Portal Cultural do mundo da Língua Portuguesa. 19 de set. de 2018. Disponível em: $<$ https://plataforma9.com/publicacoes/so cial-media-desinformacao-e-jornalismoem-campanhas-eleitorais-revista-sobrejornalismo.htm>. Acesso em 25 de jun. de 2019

WOLF, M., Teorias da comunicação. Lisboa: Presença, 1994, 2002.

WOISCHNIK, Jan. Fakes news $\mathrm{e}$ as eleições 2018. Rio de Janeiro: Fundação Konrad Adenauer, 2018.

ZANETTI, Daniela; REIS, Ruth, Comunicação e Territorialidades: poder e cultura, redes sociais e mídias. Vitória: Edufes, 2017. 